\title{
Incorporating a Flexible Manufacturing System into a Design Course
}

\author{
Salvatore A. Marsico \\ Penn State University
}

\begin{abstract}
The Associate Degree in Mechanical Engineering Technology program as offered by Penn State University requires a series of three courses in industrial engineering technology. The educational objectives of these courses are to provide students an understanding of fundamental concepts in manufacturing, materials processing, and production design. To promote a working knowledge of production design students are required to take an accompanying course production design laboratory. During the pre-bench top era this laboratory course was offered during a summer session at the end of the freshman year. This format provided students with a common laboratory experience. However, the summer laboratory experience lacked the capacity to correlate lecture materials with actual laboratory exercises. This disjoint provided stimulus for change, and change did occur in the form of two concurrent course offerings. In response to these changes each campus location of Penn State University offering the associate degree in mechanical engineering technology was required to procure equipment for these course offerings. In conjunction with a grant received from The Society of Manufacturing Engineers (SME), donor contributions, state vocational money, and matching funds from the local campus administration bench top equipment was purchased. The equipment included a CNC milling machine, a CNC lathe, a conveyor belt, gravity feeder, and a linear slide base mounted six axis robot This paper documents how the bench top equipment was arranged into a flexible manufacturing system, integrated into the laboratory course, and used for a robotics competition sponsored by SME.
\end{abstract}

\section{INTRODUCTION}

The changes brought about by technology place great pressure on universities to integrate technology into educational programs. It is no different at Penn State University. The University is comprised of a number of campuses geographically dispersed throughout the state. At many of these campuses associate degree programs in technology are offered. Prior to the advent of bench-top machining and robotic equipment associate degree students were required to attend a summer institute. The institute focused on industrial engineering processes and equipment with an emphasis on laboratory exercises. This format placed an additional financial burden on location bound students. Not only did they have to attend but also were required to pay room and board.

With the advent of bench-top technologies faculty saw an opportunity to make changes to the delivery of course content within specific technical programs. In this instance, these changes included the removal of the summer institute as a required course and replaced it with a course during the fourth and final semester of the associate degree program. While this change provided a winning combination for students, it caused great financial hardship for each of the campuses offering technology programs. The equipment was purchased with the aid of a vocational 
education grant administered through the department of education, the campus advisory board, and the Society of Manufacturing Engineers. It is the intent of this article to discuss some of the changes made to the course, and how it was transformed into a capstone course focused on flexible manufacturing.

\section{PRE BENCH-TOP}

The lecture and laboratory courses were not concurrent. The former was offered in the spring semester of the sophomore year. The latter was offered during a summer session at the completion of the freshman spring semester. This created a problem for many students because the laboratory assignments were completed almost a full academic year apart. For example, many topics such as speeds and feeds for machining operations, jigs, fixtures, and die design would not get proper coverage. This material was offered in the third course of the industrial engineering technology sequence. That is classical cart before the horse mentality; create a product and then discuss the theory. Because of the lack of equipment students were taken to facilities that showcased a particular manufacturing process.

The production design course focused on four projects to highlight and discuss the required course content. The class was divided into groups of two and given a project which would be required to be completed within four weeks. The four projects were:

- turret lathe,

- automatic screw machine,

- jigs/fixture design, and

- die design.

Concurrent with each assignment, manufacturing sites were visited to highlight a particular manufacturing concept. Grading for each project consisted of quizzes, preliminary reports, and final reports.

\section{FLEXIBLE MANUFACTURING SYSTEM}

Automation took on a whole new dimension in the mid twentieth century with the introduction of numerical control (NC) machine tools. (Manufacturing Engineering and Technology §38.2.1). Prior to this breakthrough automatic screw machines and turret lathes were the preeminent machine tools in use. (Id.) Rapid deployment of NC machine tools and the refinement of the computer chip enabled manufacturing to undergo major changes. And that is exactly what the bench-top equipment has enabled technology programs like ours to experience. We went from teaching 1950's technology to the current state of technology.

Automation has advanced manufacturing and productivity by focusing on integrating manufacturing activities. That is, manufacturing operations and processes have been arranged in efficient ways to maximize production and minimize overall costs. And the management of these operations and processes is referred to as a system. (Id. at 1067). A flexible manufacturing system is made up of a number of manufacturing cells that communicate with a material handling system via a central processor. (Id. at 1088) The manufacturing cells which make up the manufacturing system are made up of a number of machine tools that communicate and are connected to a robot. (Id.) These flexible manufacturing systems enhance both efficiency and productivity in an automated manufacturing environment. Systems typically integrate robots, a wide variety of machine tools, material handling equipment, packaging devices, sensors, actuators, controllers, and similar other hardware. ${ }^{1}$ Furthermore, flexible manufacturing systems 
take advantage of the production floor-space envelope by enabling the cells to be organized in various configurations such as $U$ shape, in-line, and L shape. These flexible manufacturing systems (FMS) having sets of numerically controlled machine tools connected to computer controlled material handling systems are key to the success of medium volume batch production. ${ }^{2}$ The benefits of an FMS (Manufacturing Engineering and Technology at 1091), as compared to a conventional system, are:

- very small batch sizes can be produced,

- labor and inventories are reduced,

- lead times for product changes are shorter,

- more reliable production, and

- work-in-progress (WIP) inventories are reduced.

The basic machines of an FMS ((Id. at 1088) used to machine parts are:

- three to five axis machining centers,

- CNC lathes,

- milling machines,

- drill presses,

- grinders.

The flexible manufacturing system used for our purposes included the following:

- $\mathrm{CNC}$ lathe,

- CNC milling machine,

- gravity feeder,

- linear slide base mounted robot,

- conveyor system,

- a stationary stepper motor driven robot arm. (Appendix E).

The strength of a manufacturing system is its ability to respond effectively to changing demands. ${ }^{3}$ Flexible manufacturing systems (FMSs) react appropriately to change. (Id.) The lathe, milling machine, and robot each had an individual computer for control purposes. Each group of two to three students rotated through each machine until the rotation was complete. Thereafter, the final project was chosen and each student had an assigned task. For each of the competitions students were asked to design a useful product for the marketplace. The manufacture of which must incorporate the use of a robot in the process.

\section{POST BENCH-TOP}

With the addition of bench-top computer controlled machining and robotics equipment many of the problems were eliminated. However, the subject matter of the course remained intact. The changes were made to the projects. Instead of the four projects students were given a number of shorter assignments that focused on application of theory. For example, when machining was discussed and that a turret lathe should be used for the project students designed the part using a computer aided design (CAD) package, wrote the coding required and machined the part on the bench top CNC lathe (Appendix A Figure 1). For all exercises students were required to include a design of the product using AutoCad, bill of materials, Geometric and Machining ( $\mathrm{G} \& \mathrm{M}$ codes- Appendix A Figure 2) code sheet, CAM produced G \& M code sheet (Appendix A Figure 3), emulation run (Appendix A Figure 4), and finished product. Each project was valued at fifteen percent and each subset of grades was weighted equally. The final project always 
consisted of designing a product for the marketplace. The product must be produced using a flexible manufacturing system. (Appendix A Figure 5) And the result must be reproduced at the annual competition held by the Robotics Division of the Society of Manufacturing Engineers. This final project was valued at forty percent whereby twenty percent was earned before reaching the robotics competition and twenty percent for attending and competing. All of the costs associated with attending the competition were paid through club and department support.

\section{PROJECTS}

Students were evaluated based on a total of eleven projects one of which included the final project that was dictated by the robotics competition. Ten projects were as follows: four on the lathe (Figure 7), four on the mill (Figure 8), and two that centered on the use of the linear slide mounted robot interacting with the material handling equipment (Figure 6).

The projects to be performed on the machine tools were designed for students to gain a fundamental understanding of the machine tool capabilities and to understand the design through manufacture process. For each assignment students were required to generate a computer aided drawing (CAD), generate the appropriate machine coding, check the code by running an emulation, and execute a production run. For projects two through four of the machine tools the CAD design was exported to the machine tools CAM capabilities so that the machine could generate the necessary coding.

The lathe projects were: (1) simple facing and turning, (2) threading, (3) complex turning which included necking, chamfering, and radius turning, and (4) taper turning. (Figure 7). The lathe was outfitted with a pneumatic chuck limited to $3 / 4$ inch stock. The stock used for the projects was aluminum 6061-T6 donated by a local supplier. The projects designated for the mill (machining center) were: 1) drilling, 2) milling of a shoulder using tool compensation, 3) milling of square pockets, and 4) milling hexagonal cuts. (Figure 8). The material used for the milling project was wax and held in place by a pneumatic vise having a fixture capacity of $2 \times 2 \times 3 / 4$. The projects assigned for the closed loop ${ }^{4}$ robotic system (Figure 6) outfitted with an air gripper were to use the teach pendant to 1) teach motion from the gravity feeder to the conveyor belt, and 2) teach motion from the conveyor belt to the lathe and to the machining center. (Figure 5). The final project was to incorporate the components of the FMS in such a way as to fit into a four foot by eight foot footprint having a maximum height of eight feet. In addition, the FMS was to include safeguards ${ }^{5}$ to insure operator and employee passerby safety. For this project all students were collaborating as a team. The team elected a team leader responsible for all communication between the team and judges at the competition. The team was divided into groups each having responsibility for a given portion of the FMS. For example, one team would be responsible for designing safety features while another would be responsible for procuring necessary materials, etc. Since the machining center did not have sliding safety doors students manufactured a set of sliding air actuated Plexiglas doors similar to those of the lathe. These doors provided access to the robotic arm and at the same time prevented any intrusion by the operator or visitors. A series of safety sensors including a floor mat and photoelectric ${ }^{6}$ devices connected to audible and visual alarms protected the working envelope of the FMS.

\section{CONCLUSION}

The change to bench top FMS instruction methodology has proven to be a windfall for the students and faculty. Not only has technology enhanced the learning process but it has produced 
students with the ability to more effectively communicate because of the interactive nature of collaborative problem solving. Furthermore, the FMS related projects have enabled faculty to more fully explore the outer limits of the work cell machine tools. This has increased the number of possible configurations for the equipment. Last but not least, the robotics competition was the incubator for the engineers of tomorrow.

\section{REFERENCES}

1. Rehg, J.A., Introduction to Robotics in CIM Systems, Prentice Hall, NJ.

2. Kalpakjian, S., R.S. Schmid, Manufacturing Engineering and Technology, $4^{\text {th }}$ ed., Prentice Hall, NJ.

3. Donaldson, C., H. G. LeClain, V.C. Goold, Tool and Die Design $3^{\text {rd }}$ ed, Glencoe

4. Campbell, P., Basic Fixture Design, Industrial Press, Inc., NY

5. Modular Fixturing Handbook, Carr Lane Manufacturing Co.

6. Tool Designers Handbook, Carr Lane Manufacturing Co.

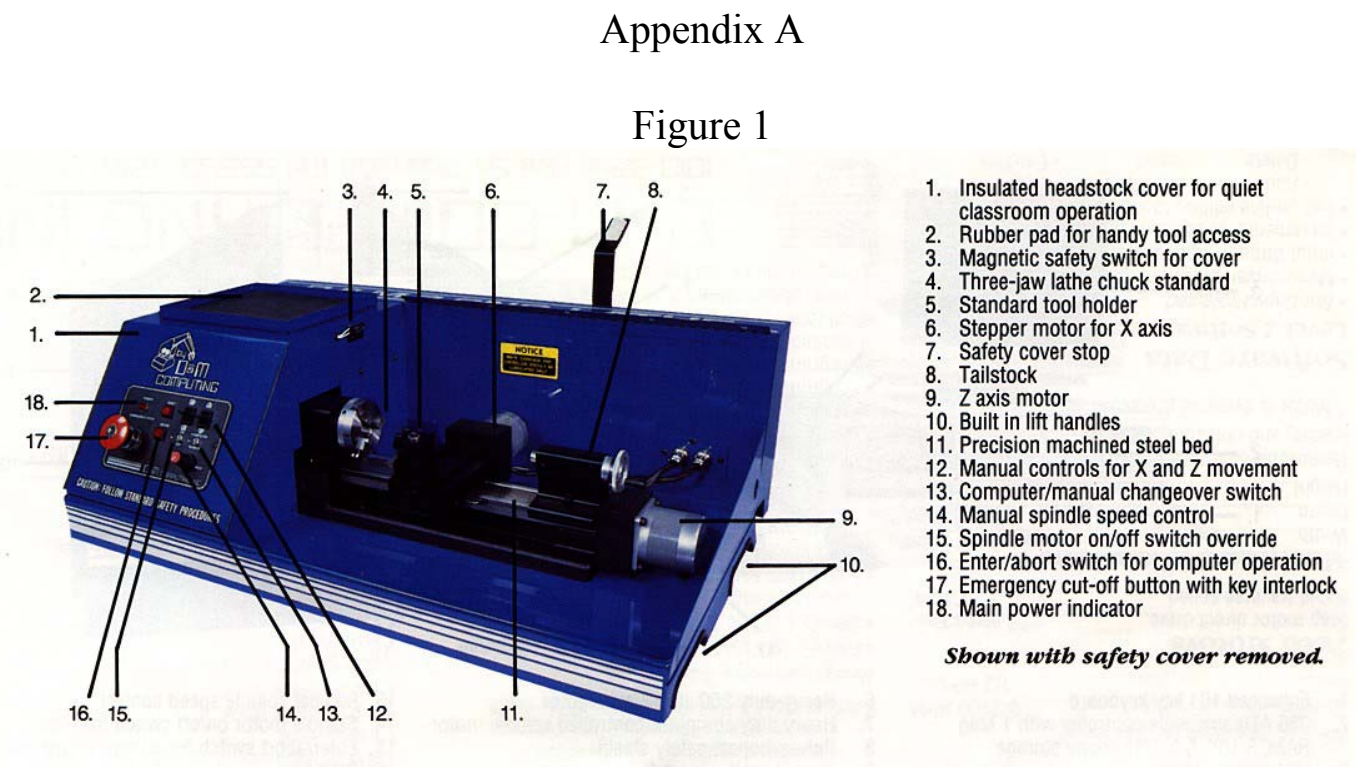

Figure 2

G \& M Codes 


\section{G - CODES SUPPORTED BY LEVEL 3 SOFT IARE}

Rapla travarse

Linear interpolation

Clrcular interpiation clockwied

Circular interpoletion counter clookwise

Dwell

subroutine call

Repeat loop atar

repeat loop an

radiur compeneation ofe

Tool mose redis compen

Imperial das programolno (1nches)

Metric data programing (milismotore)

Multipas= threading cycle

Canned turning cycle

Canned racing cycle

Canned tapex cycle

Canned circular intarpolation clockwleo

Canned circular interpolation counter clock

-wise

Absolute position programing

Incremental position programing

zero position preset

zero position reset

Feed per minute.

reed pex revolution

subroutsne label/staxt

U - CODES SUPPORTED BY LEVEL 3 SCFTTARE

MO.

Spindle on

spindie off

ToOl change

coolant on

coolant off

send output high

Send output low

Walt for input high

wait for input low

Right hand tapers/arce

Left hand tapers/arcs

Repeat loop start

Repeat $100 p$ and

stop and home

Stop and repeat

Subroutine label

Subroutine call

Subroutine and

Figure 3

G \& M Code Sheet for Machining Center

\begin{tabular}{|c|c|}
\hline LEVEL 3 & MILL SOFTWARE \\
CONTINUATION & PROGRAMMING SHEET \\
\hline
\end{tabular}

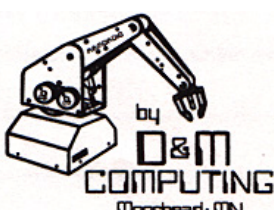

Program Name

\begin{tabular}{|l|l|l|l|}
\hline Sheet \# & & of & \\
\hline
\end{tabular}

PART Program continued

\begin{tabular}{||c|c|c|}
\hline Line \# & Instruction & Comment \\
\hline & & \\
\hline & & \\
\hline & & \\
\hline
\end{tabular}

Figure 4 


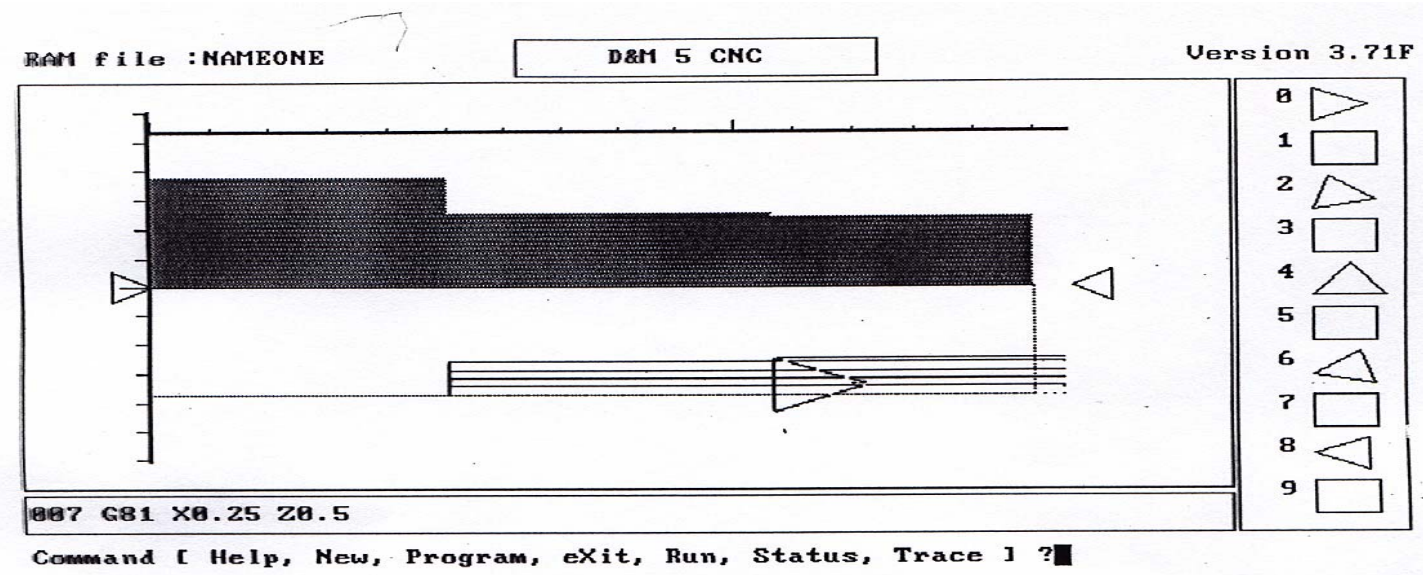

EMULATION SCREEN WITH TOOL PATH

Figure 5

FMS optional layout

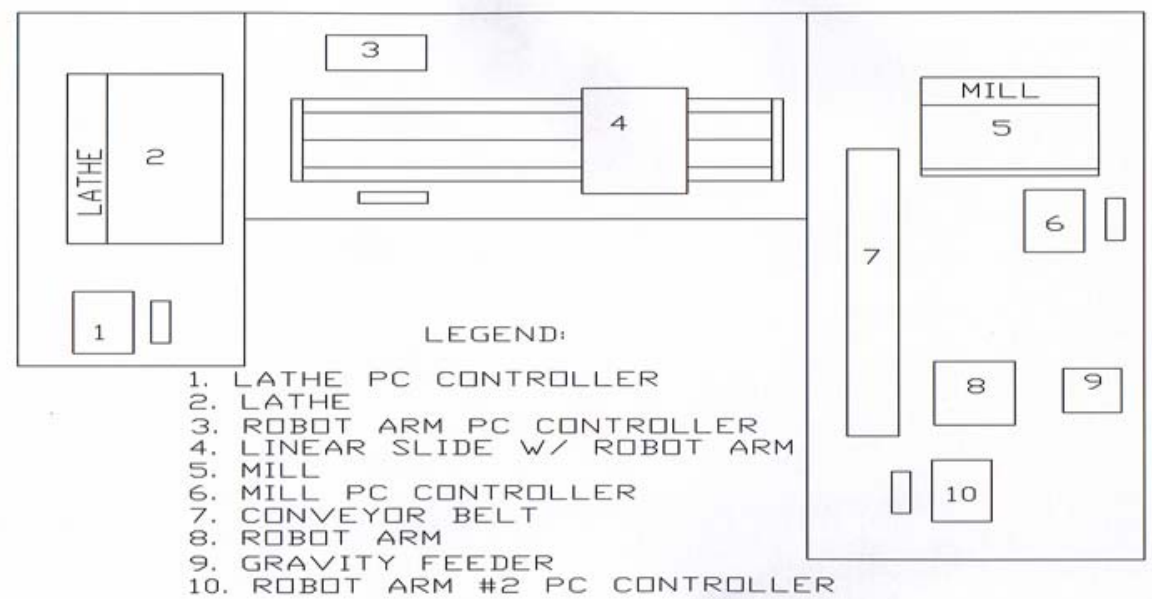

Figure 6

Robotic Systems 

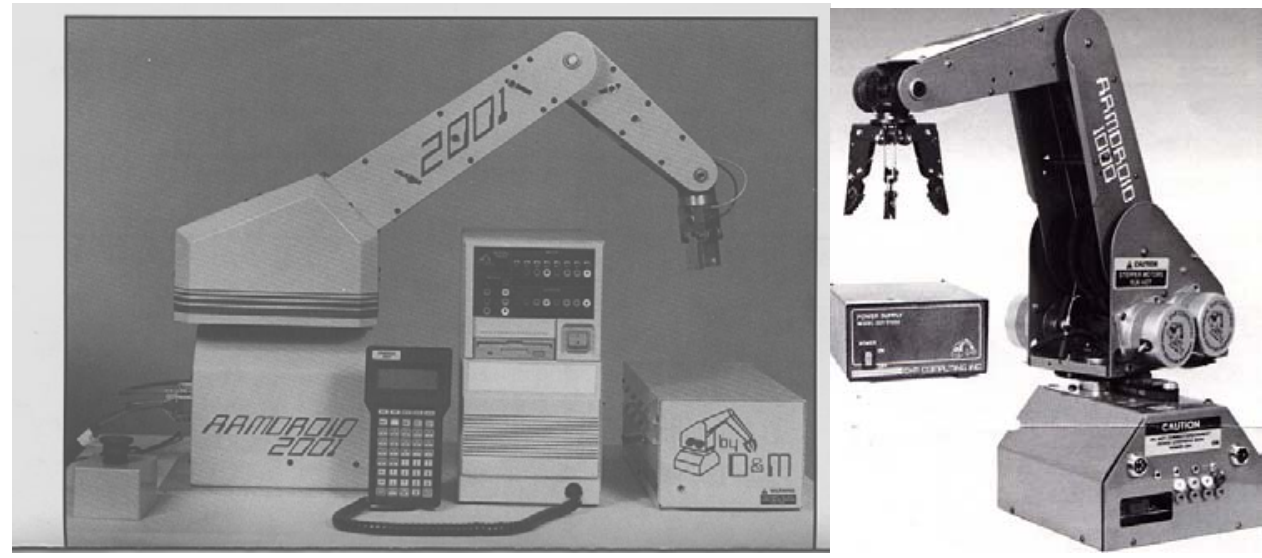

Figure 7

Turning Exercises

PROJECT \#1 - G81 CANNED TURNING

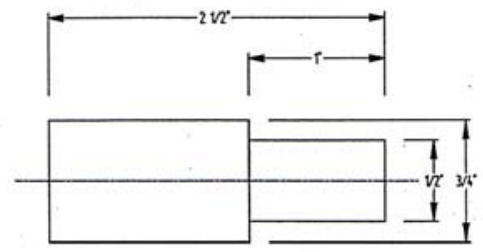

PROJECT \#8

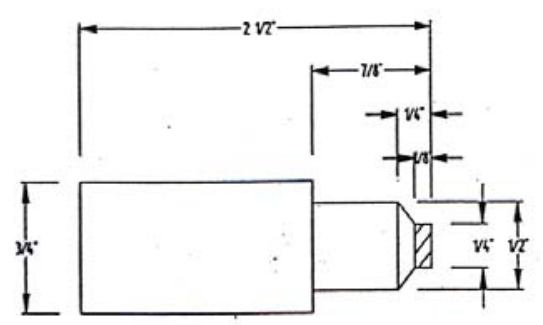

MATERIALS: ALUMINIUM

SPECIFICATIONS: $3 / 4^{\prime \prime} \times 1$ 1/2"

ROUGH CUT: 30 THOUSANDS

FINISHED CUT: 10 THOUSANDS

FEED RATE: 3 INCHES PER MINUTE

SPINDLE SPEED: 1300 RPM

TOOL: 0 (RIGHT HAND TURNING)

Figure 8

Machining Center 


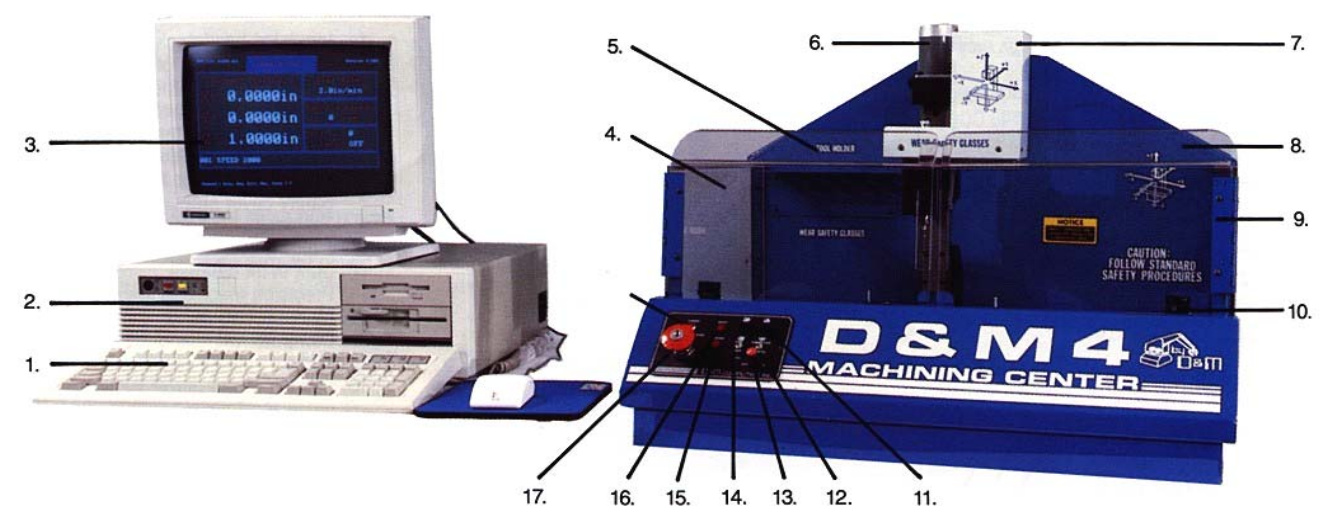

1. Enhanced 101 key keyboard 2. 286 AT compatible controller with $1 \mathrm{Meg}$ RAM, $31 / 2$ " \& $51 / 4$ " floppy storage VGA color monitor

Removable polycarbonate safety shield for easy robot access (left or right side)

6. Heavy-duty 200 step $Z$ axis motor 7. Heavy duty computer controlled spindle motor 8. Polycarbonate safety shield

9. Hinged safety doors for easy access

10. Magnetic safety interlock

11. Manual controls for $X$, $Y$ and $Z$ movement Spare tool holder rack

12. Computer/manual changeover switch

13. Manual spindle speed control

14. Spindle motor on/off switch override

15. Enter/abort switch for computer operation

16. Shift key

17. Emergency cut-off button with key interlock

18. Main power indicator
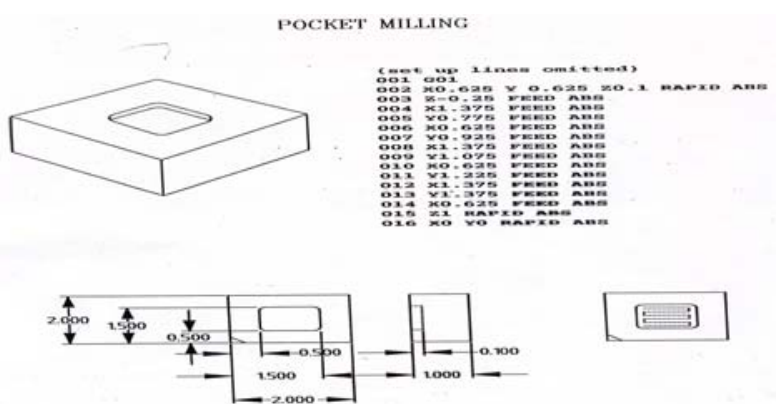

\footnotetext{
${ }^{1}$ Garg, D.P., Poppe, C.D., Coordinated robots in a flexible manufacturing work cell, International Conference on Advanced Intelligent Mechatronics, AIM Proceedings.

${ }^{2}$ El Maraghy, H.A. Ravi, T., Modern tools for the design, modelling and evaluation of flexible manufacturing systems. Robotics and Computer-Integrated Manufacturing, v 9, n 4-5, Aug-Oct, 1992, 4th International Conference on the Manufacturing Science and Technology of the Future.

${ }^{3}$ Rajamani, D. Kumar,A.G., Machine loading in flexible manufacturing systems considering routeing flexibility, International Journal of Advanced Manufacturing Technology, v11, 5, 1996, p 372-380, Springer-Verlag London Ltd., London, UK

${ }_{5}^{4}$ Rehg, J.A., Introduction to Robotics in CIM Systems $3{ }^{\text {rd }}$ ed., Prentice Hall, NJ, pg63.

${ }^{5}$ Id. at 293

${ }^{6}$ Id. at 167
}

Salvatore A. Marsico, is an Assistant Professor of Mechanical Engineering and Legal Issues in Engineering in the Commonwealth College of Penn State University 